\title{
The Role of Perceived Job Stress in the Relationship between Smoking and the Development of Peptic Ulcers
}

\author{
Jun Shigemi, Yoshio Mino, and Toshihide Tsuda
}

\begin{abstract}
Although smoking has been considered a risk factor in causing pepticulcers, no study has examined the effects of job stress on the relationship between peptic ulcers and smoking. To establish a link between gastric or duodenal ulcers over two years and a state of perceived job stress, a questionnaire, including questions on demographics, smoking, history of peptic ulcer and perceived job stress was conducted. Follow-up surveys were carried out every six months to accumulate the data for this analysis and the time span of this follow up study was two years. To examine the role of perceived job stress on the relationship between smoking and peptic ulcers, stratified analyses were performed.Some specific causes of perceived job stress such as "Too much competition," "Schedule is too tight or pressed to work too hard" had high estimated relative risks: 2.13 with $95 \%$ confidence interval $(\mathrm{Cl})$ of $1.09-4.16$ and 2.50 with $95 \% \mathrm{Cl}$ of 0.98 6.40 , respectively. Stratified analyses suggested an effect-measure modification of perceived job stress in the relationship between peptic ulcers and smoking. Multiplicative and additive models suggest positive interaction between perceived job stress and smoking. These results suggest that specific perceived job stress is an effect modifier in the relationship between the history of the peptic ulcer and smoking. J Epidemiol, $1999 ; 9: 320-326$
\end{abstract}

perceived job stress, peptic ulcer, smoking habit, effect-measure modification, follow up study

Peptic ulcers are one of the prevalent diseases in the alimentary tract. It has been established that non-steroidal anti-inflammatory drug (NSAID) and smoking are major risk factors for this disease ${ }^{1)}$. Recently, Helicobacter pylori has received attention as a representative causal factor of peptic ulcers. 1 In Japan, the life-time risk of active or inactive peptic ulcers in male workers was estimated at $23 \%, 2$ and the incidence rate at $5 \%$ per year or more ${ }^{2}$. Thus, peptic ulcers are a work-related disease because of an increased prevalence of peptic ulcers found among certain segments of working population ${ }^{3}$. Accordingly, occupational factors such as job stress are suspected as risk factors for peptic ulcers. However, there are few studies ${ }^{4)}$ examining the relationship between job stress and peptic ulcers.

Many studies ${ }^{5-10)}$ have been performed to investigate the causal relationship between peptic ulcers and smoking. It is established that smoking is one of the risk factors for peptic
ulcers.There has been no study, however, investigating the effects of job stress on the relationship between smoking and peptic ulcers.

The purpose of our research was to investigate the relationship between perceived job stress, smoking and peptic ulcers, particularly to clarify the effect of perceived job stress on the relationship between smoking and peptic ulcers.

\section{MATERIALS AND METHODS}

The study subjects comprised of employees of a middlesized company producing minute electric parts in Japan. We conducted a follow up study over two years, during which the questionnaire surveys were performed every six months to obtain information about gastric or duodenal ulcers. In the surveys, a self-administered questionnaire posed questions about smoking habits, perceived job stress ${ }^{\text {II) }}$, previous or current gas-

Received December 16, 1998 ; accepted February 14, 1999.

Department of Hygiene and Preventive Medicine, Okayama University Medical School, 2-5-1, Shikata-cho, Okayama, 700-8558, Japan.

Address for correspondence : Jun Shigemi, Department of Hygiene and Preventive Medicine, Okayama University Medical School, 2-5-1, Shikata-cho, Okayama, 700-8558, Japan. 
tric or duodenal ulcers, and additional questions about the workers demographics.

Among 782 workers, 763 workers $(97.6 \%)$ answered the questionnaire satisfactorily in the baseline survey. During the follow up, 140 workers dropped out, and prevalent cases of peptic ulcers numbered 39. In the follow up study, we eliminated the prevalent cases mentioned above in the baseline survey. Consequently, 584 workers were eligible for this study and there were 32 incidences of peptic ulcers over the two years. Response rate of eligible workers was $76.5 \%$ and not high value. To examine workers gastric or duodenal ulcer history, each respondent was asked the question: "Have you ever had medical treatment for a gastric or duodenal ulcer ?" Based on the answer that workers gave to this question, they were divided into two groups; the men newly treated for peptic ulcers during the follow up period and the rest. We regarded, the former as newly detected cases of peptic ulcers and the latter as non-ulcer subjects.

Because peptic ulcers were defined as work-related disease ${ }^{5)}$, we used the job stress questionnaire as recognition of job stress. However, this questionnaire has not been validated. On the otrher hand, this questionnaire has been already used in the relationship between peptic ulcer and work-related factors ${ }^{10)}$. In addition to this contents, as we considered that this questionnaire covered various types of perceived job stress, this questionnaire was selected. The job stress questionnaire ${ }^{12)}$ consisted of the 13 items which are described in Table 2. For each item, we defined those who answered "yes, frequently" or yes, sometimes" as positive and those who answered "almost never" as negative for each item. In our previous study ${ }^{26)}$, we calculated a reliable measure. In this result, Cronbach's alpha coefficient was 0.80 , which is thought to be a high value of reliable measure in this questionnaire.

To check on smoking habits, we asked a dichotomous question to workers, "smoking" or "non smoking".

We hypothesized that perceived job stress contributes to developing peptic ulcers. In particular, that specific items of perceived job stress effect the relationship between smoking and developing peptic ulcers as a confounder, or as an effect modifier.Stratified analysis of perceived job stress about the relationship between smoking and peptic ulcers was carried out. To examine multiplicative interaction between job stress and smoking habit, we carried out a multiple logistic regression analysis. As Aldoori et al ${ }^{13}$ ). reported little association between caffeine and risk of duodenal ulcers and Brenner et al ${ }^{14}$. suggested the protective effect of alcohol consumption against active infection with Helicobacter pylori and the opposite effect with coffee consumption, we adjusted for the effects of alcohol and coffee consumption in the analysis of the multiple logistic regression model. Since age was significantly related to smoking proportion by chi-square test, we considered age a confounding factor. In addition to the multiplicative interaction model, we used an additive model and we calculated the interaction constant ratio (ICR) in accordance with Rothman and Greenland's textbook ${ }^{15)}$ because, epidemiologically, the additive interactive model is an important idea, especially in the area of public health. We did these analyses using the computer programs SPSS-Windows ${ }^{16)}$ and Epi-Info ${ }^{17}$.

\section{RESULTS}

The demographics of workers who responded to our study in the eligible population are shown in Table 1.The smoking percentages were $57.8 \%$ of males, $5.6 \%$ of females. The distribution of job type in the incident cases of peptic ulcer was 17/298 in the department of production, 6/98 in the department of technology and development, $3 / 45$ in the department of investigation and inspection, and 6/129 in the department of management. Table 2 shows crude relative risks in the relationship between perceived job stress and peptic ulcers in the follow up study. The item "Too much competition" had a significant relationship with peptic ulcer incidence. Although the chi-square test was not significant, partly because of a small number of cases, the item of perceived job stress: "Schedule is too tight or

Table 1.

\begin{tabular}{llcl}
\hline \multicolumn{3}{c}{ Demographics of eligible workers who participated in our survey. } \\
\hline Sex & Male & 296 & $(50.6 \%)$ \\
& Female & 289 & $(49.4 \%)$ \\
& Total & 585 & \\
& & & \\
Age & $-29 \mathrm{yr}$ & 235 & $(40.2 \%)$ \\
& $30-39 \mathrm{yr}$ & 160 & $(27.4 \%)$ \\
& $40-49 \mathrm{yr}$ & 175 & $(30.0 \%)$ \\
& $50+\mathrm{yr}$ & 14 & $(2.4 \%)$ \\
& Total & 584 & $(100 \%)$
\end{tabular}

Departments

$\begin{array}{lrl}\text { Business } & 8 & (1.4 \%) \\ \text { Production } & 298 & (50.9 \%) \\ \text { Technology and } & & \\ \quad \text { Developement } & 98 & (16.8 \%) \\ \text { Investigation } & & \\ \quad \text { and Inspection } & 45 & (7.6 \%) \\ \text { Personnel } & 7 & (1.2 \%) \\ \text { Management } & 129 & (22.1 \%) \\ \text { Total } & 585 & (100 \%)\end{array}$

Smoking Percentages

$\begin{array}{llrl}\text { Sex } & \text { Male } & 171 / 296 & (57.8 \%) \\ & \text { Female } & 16 / 289 & (5.6 \%)\end{array} \mathrm{p}<0.001$


pressed to work too hard" showed a relative risk ( $95 \%$ confidence interval) of 2.5 (0.98-6.40). Results of multiple logistic regression analysis controlling gender, age, smoking and other potential confounders were shown in table 3 .In this results, the item "Schedule is too tight or pressed to work too hard" showed 2.00 of point estimated odds ratio. However, this measure was not significant partly because of small sample size.

The results of stratified analysis on perceived job stress are shown in Table 4. In several items of perceived job stress, smoking status, and peptic ulcer, relative risks of smoking for peptic ulcer were larger in the stress group than in the nonstress group, with significant relative risks observed in the stress group, and non-perceived job stress groups showing no significant relationship. These risks were linked to the items such as "Too much trouble at work," "Too much responsibility," "Work hours too long," "Feel pressed for time," and "Shortage of workers". This discrepancy between the job stress group and the non stress group in the stratified analyses suggests effect-measure modification of specific perceived job stress.

The results of the multiple logistic regression models with interaction between perceived job stress and smoking are shown in Table 5. There were five items of job stress which suspected multiplicative positive interaction because of more

Table 2. Relative risks (RR) between perceived job stress and peptic ulcers by crude analysis.

\begin{tabular}{|c|c|c|c|c|c|c|}
\hline Item of perceived job stress & $\begin{array}{l}\text { stress } \\
\text { case }\end{array}$ & $\begin{array}{c}\text { group } \\
\text { non-case }\end{array}$ & $\begin{array}{l}\text { non-stress } \\
\text { case }\end{array}$ & $\begin{array}{c}\text { group } \\
\text { non-case }\end{array}$ & $\mathbf{R R}$ & $95 \%$ confidence interval \\
\hline 1. Too much competition & 16 & 169 & 6 & 388 & 2.13 & $(1.09-4.16)$ \\
\hline 2. Too much work & 24 & 371 & 8 & 182 & 1.44 & $(0.66-3.15)$ \\
\hline $\begin{array}{l}\text { 3. Schedule is too tight or } \\
\text { pressed to work too hard }\end{array}$ & 27 & 372 & 5 & 180 & 2.50 & $(0.98-6.40)$ \\
\hline 4. Too much tronble at work & 25 & 360 & 7 & 190 & 1.83 & $(0.80-4.15)$ \\
\hline 5. Too much responsibility & 23 & 316 & 9 & 232 & 1.82 & $(0.86-3.86)$ \\
\hline 6. Work hours too long & 18 & 234 & 13 & 313 & 1.79 & $(0.89-3.59)$ \\
\hline 7. Poor relationship with superiors & 12 & 173 & 20 & 374 & 1.28 & $(0.64-2.56)$ \\
\hline 8. Feel pressed for time & 25 & 395 & 7 & 157 & 1.39 & $(0.62-3.16)$ \\
\hline 9. Are not allowed to make mistakes & 28 & 454 & 4 & 97 & 1.47 & $(0.53-4.09)$ \\
\hline 10. Shortage of workers & 22 & 284 & 10 & 265 & 1.98 & $(0.95-4.10)$ \\
\hline $\begin{array}{l}\text { 11. Must entertain guests at night } \\
\text { and weekends too much }\end{array}$ & 1 & 21 & 31 & 523 & 0.78 & $(0.11-5.45)$ \\
\hline 12. Labor too strenuous & 14 & 175 & 18 & 375 & 1.62 & $(0.82-2.18)$ \\
\hline 13. Canot keep up with new technology & 17 & 217 & 15 & 330 & 1.67 & $(0.85-3.28)$ \\
\hline
\end{tabular}

Table 3. The results of multiple logistic regression analysis of the relationship between perceived job stress and peptic ulcers adjusted for gender, age, satisfacion with family life, physical health, smoking habits, alcohol and coffee consumption.

\begin{tabular}{lcc}
\hline Perceived job stress item & adjusted risk odds ratio & $95 \%$ confidence interval \\
\hline 1. Too much competition & 1.55 & $0.70-3.43$ \\
2. Too much work & 1.04 & $0.41-2.61$ \\
3. Schedule is too tight or pressed & 2.00 & $0.66-6.06$ \\
$\quad$ work too hard & & \\
4. Too much trouble at work & 1.08 & $0.42-2.85$ \\
5. Too much responsibility & 1.37 & $0.58-3.22$ \\
6. Work hours too long & 1.37 & $0.62-3.07$ \\
7. Poor relationship with superiors & 1.14 & $0.52-2.50$ \\
8. Feel pressed for time & 0.68 & $0.25-1.86$ \\
9. Are not allowed to make mistakes & 1.62 & $0.53-5.01$ \\
10. Shortage of workers & 1.70 & $0.72-4.00$ \\
11. Must entertain guests at night & 0.79 & $0.08-6.13$ \\
$\quad$ and weekends too much & & \\
12. Labor too strenuous & 1.28 & $0.58-2.82$ \\
13. Cannot keep up with new technology & 1.14 & $0.49-2.62$ \\
\hline
\end{tabular}


Table 4. Stratified analysis between smoking and peptic ulcers by perceived job stress.

\begin{tabular}{|c|c|c|c|c|c|c|}
\hline item of perceived job stress & $\begin{array}{c}\text { risk of } \\
\text { smoking group }\end{array}$ & $\begin{array}{c}\text { risk of } \\
\text { non-smoking group }\end{array}$ & $\mathbf{R R}$ & $95 \% \mathrm{CI}$ & MHPR & $95 \% \mathrm{CI}$ \\
\hline \multicolumn{7}{|l|}{ 1. Too much competition } \\
\hline overall & & & & & 3.85 & $(1.81-8.18)$ \\
\hline non-stress & $8 / 104$ & $8 / 290$ & 2.79 & $(1.07-7.24)$ & & \\
\hline stress & $13 / 81$ & $3 / 104$ & 5.66 & $(1.64-18.87)$ & & \\
\hline \multicolumn{7}{|l|}{ 2. Too much work } \\
\hline overall & & & & & 3.89 & $(1.92-7.87)$ \\
\hline non-stress & $5 / 41$ & $3 / 149$ & 6.06 & $(1.51-24.29)$ & & \\
\hline stress & $16 / 146$ & $8 / 249$ & 3.41 & $(1.50-7.77)$ & & \\
\hline \multicolumn{7}{|l|}{$\begin{array}{l}\text { 3. Schedule is too tight or } \\
\text { pressed to work too hard }\end{array}$} \\
\hline overall & & & & & 4.05 & $(1.80-9.10)$ \\
\hline non-stress & $0 / 28$ & $5 / 157$ & - & & & \\
\hline stress & $21 / 158$ & $6 / 241$ & 5.34 & $(2.20-12.93)$ & & \\
\hline \multicolumn{7}{|l|}{ 4. Too much trouble at work } \\
\hline overall & & & & & 4.34 & $(1.90-9.89)$ \\
\hline non-stress & $1 / 30$ & $6 / 167$ & 0.93 & $(0.12-7.43)$ & & \\
\hline stress & $20 / 156$ & $5 / 229$ & 5.87 & $(2.25-15.31)$ & & \\
\hline \multicolumn{7}{|l|}{ 5. Too much responsibility } \\
\hline overall & & & & & 4.08 & $(1.91-8.72)$ \\
\hline non-stress & $3 / 57$ & $6 / 184$ & 1.61 & $(0.42-6.25)$ & & \\
\hline stress & $18 / 128$ & $5 / 211$ & 5.93 & $(2.26-15.60)$ & & \\
\hline \multicolumn{7}{|l|}{ 6. Work hours too long } \\
\hline overall & & & & & 2.81 & $(1.80-8.05)$ \\
\hline non-stress & $6 / 86$ & $7 / 239$ & 2.38 & $(0.82-3.89)$ & & \\
\hline stress & $14 / 98$ & $4 / 154$ & 5.50 & $(1.86-16.23)$ & & \\
\hline \multicolumn{7}{|c|}{ 7. Poor relationship with superiors } \\
\hline overall & & & & & 4.01 & $(1.98-8.35)$ \\
\hline non-stress & $13 / 125$ & $7 / 268$ & 3.58 & $(1.63-11.69)$ & & \\
\hline stress & $8 / 61$ & $4 / 124$ & 4.07 & $(1.27-12.97)$ & & \\
\hline \multicolumn{7}{|l|}{ 8. Feel pressed for time } \\
\hline overall & & & & & 4.11 & $(1.98-8.56)$ \\
\hline non-stress & $3 / 35$ & $4 / 128$ & 2.74 & $(0.64-11.69)$ & & \\
\hline stress & $18 / 151$ & $7 / 269$ & 4.58 & $(1.96-10.72)$ & & \\
\hline \multicolumn{7}{|c|}{ 9. Are not allowed to make mistakes } \\
\hline overall & & & & & 4.15 & $(2.04-8.43)$ \\
\hline non-stress & $3 / 37$ & $1 / 64$ & 5.19 & $(0.56-48.10)$ & & \\
\hline stress & $18 / 149$ & $10 / 333$ & 4.02 & $(1.90-8.50)$ & & \\
\hline \multicolumn{7}{|l|}{ 10. Shortage of workers } \\
\hline overall & & & & & 3.99 & $(1.83-7.87)$ \\
\hline non-stress & $5 / 65$ & $5 / 209$ & 3.22 & $(0.96-10.76)$ & & \\
\hline stress & $16 / 121$ & $6 / 185$ & 4.08 & $(1.64-10.13)$ & & \\
\hline \multicolumn{7}{|c|}{$\begin{array}{l}\text { 11. Must entertain guests at night } \\
\text { and weekends too much }\end{array}$} \\
\hline overall & & & & & 4.09 & $(2.01-8.32)$ \\
\hline non-stress & $20 / 176$ & $11 / 378$ & 3.90 & $(1.91-7.97)$ & & \\
\hline stress & $1 / 8$ & $0 / 15$ & - & & & \\
\hline \multicolumn{7}{|l|}{ 12. Labor too strenuous } \\
\hline overall & & & & & 3.95 & $(1.95-7.98)$ \\
\hline non-stress & $13 / 123$ & $5 / 269$ & 5.69 & $(2.07-15.60)$ & & \\
\hline stress & $8 / 64$ & $6 / 125$ & 2.60 & $(0.94-7.18)$ & & \\
\hline \multicolumn{7}{|c|}{ 13. Cannot keep up with new technology } \\
\hline overall & & & & & 4.05 & $(1.87-8.78)$ \\
\hline non-stress & $7 / 81$ & $8 / 264$ & 2.85 & $(1.07-7.62)$ & & \\
\hline stress & $14 / 105$ & $3 / 129$ & 5.73 & $(1.69-19.42)$ & & \\
\hline
\end{tabular}

* MHRR : Mantel-Haenszel weighted relative risk

* CI : confidence interval 
than 2.0 of exp(coefficient); "Too much trouble at work," "Too much responsibility," "Work hours too long," and "Cannot keep up with new technology." The specific items of perceived job stress, which found to be the effect-measure modifiers in the stratified analyses, showed positive multiplicative interactive effects.However, statistical tests were not significant, partly due to the same reason of small case samples.

Table 6 shows the results of additive interactive models for the five items of perceived job stress. ICR ${ }^{15}$ is the "interaction constant ratio" and has previously been labeled the "relative excess risk of interaction". If we take this as positive for additivity hypothesis, ICR shows the value of more than 0 . The same items of perceived job stress as the multiplicative interactive models indicate positive interaction; in other words "superadditivity" 15 in the relationship with smoking, because all of the ICR were more than 0 with the range of 1.78 to 3.03 .

Table 5. The multiplicative coefficient : exp (imteractive coefficient : smoking $\times$ perceived job stress) using a multiple logistic regression model.

\begin{tabular}{lcc}
\hline perceived job stress item & exp (coefficient) & $95 \%$ confidence interval \\
\hline 1. Too much competition & 2.36 & $0.43-12.8$ \\
4. Too much trouble at work & 9.19 & $0.81-104$ \\
5. Too much responsibility & 4.44 & $0.72-27.2$ \\
6. Work hours too long & 2.64 & $0.49-14.2$ \\
13. Cannot keep up with new technology & 2.30 & $0.42-12.7$ \\
\hline
\end{tabular}

Table 6. The results from the additive interactive model between perceived job stress and smoking.

Notation for risks with two binary exposure indicators such as perceived job stress and smoking

\begin{tabular}{|c|c|c|c|c|}
\hline & & smoking & $\mathrm{Z}=1$ & $\mathrm{Z}=0$ \\
\hline \multirow{2}{*}{$\begin{array}{l}\text { perceived } \\
\text { job stress }\end{array}$} & $X=1$ & & $\mathrm{R}_{11}$ & $R_{10}$ \\
\hline & $X=0$ & & $\mathrm{R}_{01}$ & $\mathbf{R}_{00}$ \\
\hline \multicolumn{2}{|l|}{ Perceived job stress item } & Risk ratio (RR) & & $95 \%$ confidence interval \\
\hline \multirow{5}{*}{\multicolumn{2}{|c|}{ 1. Too much competition }} & $R_{11} 5.82$ & & $2.50-13.55$ \\
\hline & & $R_{10} 1.05$ & & $0.28-3.87$ \\
\hline & & $R_{01} 2.79$ & & $1.07-7.24$ \\
\hline & & $R_{000} 1.00$ & & \\
\hline & & $\mathrm{ICR}=\mathrm{RR}_{11-\mathrm{R}_{1}}$ & $.01+1=2.98>0$ & \\
\hline \multirow{5}{*}{\multicolumn{2}{|c|}{ 4. Too much trouble at work }} & $R_{n} \quad 3.57$ & & $1.47-8.65$ \\
\hline & & $R_{10} \quad 0.61$ & & $0.19-1.96$ \\
\hline & & $\mathrm{RR}_{01} \quad 0.93$ & & $0.12-7.43$ \\
\hline & & $R_{00} 1.00$ & & \\
\hline & & $\mathrm{ICR}=3.03>0$ & & \\
\hline \multirow{5}{*}{\multicolumn{2}{|c|}{ 5. Too much responsibility }} & $R_{11} 4.31$ & & $1.76-10.56$ \\
\hline & & $\mathrm{RR}_{10} \quad 0.73$ & & $0.23-3.34$ \\
\hline & & $\mathrm{RR}_{01} 1.61$ & & $0.42-6.25$ \\
\hline & & $\mathrm{RR}_{00} \quad 1.00$ & & \\
\hline & & ICR $=2.97>0$ & & \\
\hline \multirow{5}{*}{\multicolumn{2}{|c|}{ 6. Work hours too long }} & $R_{11} 4.08$ & & $2.03-11.72$ \\
\hline & & $R R_{10} \quad 0.89$ & & $0.26-2.98$ \\
\hline & & $R_{01} 2.28$ & & $0.79-6.59$ \\
\hline & & $\mathrm{RR}_{0} 1.00$ & & \\
\hline & & $\mathrm{ICR}=1.91>0$ & & \\
\hline \multirow{5}{*}{$\begin{array}{l}\text { 13. Cannot keep up with } \\
\text { new technology }\end{array}$} & & $R_{11} 4.40$ & & $1.90-10.18$ \\
\hline & & $\mathrm{RR}_{10} \quad 0.77$ & & $0.21-2.84$ \\
\hline & & $R_{\text {Ro }} 2.85$ & & $1.07-7.62$ \\
\hline & & $R_{00} 1.00$ & & \\
\hline & & $\mathrm{ICR}=1.78>0$ & & \\
\hline
\end{tabular}

* ICR : Interaction constant ratio 
Consistently, these results indicate effect-measure modification or positive interaction of specific perceived job stress in the causal relationship between smoking and developing peptic ulcers.

\section{DISCUSSION}

Araki ${ }^{2)}$ reported that the life-time risk of active and inactive peptic ulcers was $23 \%$ in male workers aged $31-60$ and that the incidence of active and inactive peptic ulcers over one year was $5 \%$ or more. In our follow up study over two years, 584 workers were eligible and 32 cases had a history of peptic ulcers over the two years, which indicate a $5.5 \%$ risk of peptic ulcer over two years.

In Japan, Araki ${ }^{18}$ failed to find an association between medically diagnosed peptic ulcers and frustration at work in his case-control study. On the other hand, Sugisawa and Uehata ${ }^{10}$ claimed that there was a relationship between perceived job stress and peptic ulcers in their follow up study. In other countries, several researchers ${ }^{19,20)}$ suggested the relationship between self-perceived stress and peptic ulcers. The findings in this study were consistent with those of the latter three studies. In Araki's study ${ }^{18}$, he asked only about job stress frustration, so he might fail to find the relationship between job stress and peptic ulcers.

Many studies ${ }^{5-10)}$ have concluded that smoking is a risk factor for peptic ulcers. Therefore, we conducted the stratified analysis using perceived job stress in order to evaluate the effects of job stress on the relationship between smoking and peptic ulcers. Our results suggest that specific perceived job stress is an effect-measure modifier ${ }^{15)}$ rather than a confounder.

In addition to stratified analysis, we analyzed the statistical interaction between smoking habits and perceived job stress.Statistical interaction is considered to be equivalent to effect-measure modificationin an epidemiology textbook ${ }^{15}$ ) However, Rothman and Greenland explain in their textbook ${ }^{15)}$ that the term "effect modification" is also ambiguous, and they advise more precise terms such as "risk-difference modification" or "risk-ratio modification," as appropriate. In this case, we used the term "risk-ratio modification" in the stratified analysis.

Initially, we analyzed multiplicative interaction with multiple logistic regression analysis because most epidemiological statistics are based on multiplicative models. Although statistical tests were not significant, partly because of the small sample size, they suggest a multiplicative positive interaction between smoking and perceived job stress.

However, Rothman and Greenland ${ }^{15)}$ point out that statistical interaction is a phenomenon whose presence or absence, as well as magnitude, is entirely determined by the scale chosen for measuring additivity of the effects. Accordingly, we calcu- lated the additive interaction between smoking and perceived job stress. In the pointed estimated risk ratio, these results showed positive interaction between smoking and specific perceived job stress such as "Too much competition," "Too much trouble at work," "Too much responsibility," "Work hours too long", and "Cannot keep up with new technology" in the relationship with peptic ulcers.

In the stratified analysis, the item of perceived job stress "Labor too strenuous" showed the opposite result compared to the items "Too much trouble at work," "Too much responsibility," and "Work hours too long". Using cross-table analysis, many workers who answered negatively for perceived job stress, had specific perceived job stress which included the latter items. For this reason, the item "Labor too strenuous" may generate the opposite result.

In these analyses, the proportions of perceived job stress were higher in smoking group than in non smoking group. These results are suspected that the stress was enhanced because of smoking. About the relationship between perceived job stress and withdrawal symptoms of nicotine, the cases who stopped smoking in our follow up study were only about 20. Adding this content, duration of withdrawal symptoms of nicotine was generally within two weeks at the longest. For these reasons, it is difficult that withdrawing nicotine affects to perceived job stress in our study.

Lastly, we discuss the limitations of this study. Firstly, our sample size were relatively small. Consequently, some statistical tests may not yield significant results. Further study is required with a larger sample to investigate the relationship between perceived job stress and peptic ulcer and to confirm the effect-measure modification of job stress in the relationship between smoking and peptic ulcers.

Secondly, the response rate of eligible workers was $76.5 \%$. These results suggested that we should pay attention to selection bias. However, because there were no significant differences among demografic variables between eligible workers and workers lost in follow-up, a possibility of selection bias might be small.

In addition, we collected information on peptic ulcers using a self-administered questionnaire with no clinically diagnostic confirmation. Therefore, there could be a bias in the information collecting process. However, major bias is thought to be a non-differential misclassification in our study, so the magnitude of the effects may be underestimated ${ }^{15}$.

We did not get information on Helicobacter pylori infection as a potential confounder of the relationship ${ }^{21-25)}$. Since the purpose of this study was to investigate the causal relationship between perceived job stress and peptic ulcers, it is unlikely that Helicobacter pylori infection is related to the perceived job stress of the workers. Therefore, an infection with Helicobacter pylori does not satisfy sufficient criteria15 as a confounding factor. 
As stated, we used a self-administered questionnaire consisting of 13 items to evaluate perceived job stress. The validity of this questionnaire was not evaluated prior to the study. It is doubtful whether all the perceived job stresses items in the Japanese workers could be generally or accurately covered by this questionnaire. However, this questionnaire has already been used in the study of occupational stress-related cardiovascular disease and of mental health in Japanese workers ${ }^{12,26-27}$.

In conclusion, the results of this study suggest that perceived job stress items such as "Too much competition" could be risk factor for developing peptic ulcers. Specific perceived job stress could have an effect-measure modification on the relationship between smoking habits and developing peptic ulcers. Both the multiplicative and the additive interaction models suggest positive interaction between specific items of perceived job stress and smoking.

\section{REFERENCES}

1. Harrison's Principles of Internal Medicine 14th Edition MacGraw Hill, 1998:1596-1610.

2. Araki S.Peptic ulcer in male factory workers: a survey of prevalence, incidence, and aetiological factors. $J$ Epidemiol and Community Health 1985; 39: 82-85.

3. Report of a WHO expert committee. Identification and control of work-related disease.WHO Tech Rep Ser No.714. Geneve: (WHO 1985) 7-21.

4. Hamajima N, Aoki K, Sasaki R, Yamada T, Asano A, Mizuno S. A workplace-based case-control study of gastric ulcer among male municipal employees in Japan. Jpn J Med 1987; 26: 326-31.

5. Kato I, Nomura AMY, Stemmermann GN, Chyou P. A prospective study of gastric and duodenal ulcer and its relation to smoking, alcohol, and diet. Am J Epidemiol 1992; 135: 521-30.

6. Johnsen R, Forde OH, Straume B, Burhol P. Aetiology of peptic ulcer: a prospective population study in Norway. $J$ Epidemiol and Community Health 1994; 48: 156-60.

7. Eastwood GL. Is smoking still important in the pathogenesis of peptic ulcer disease? J Clin Gastroenterol 1997; 25 (suppl.1): 1-7.

8. Kurata JH, Nogawa AN.Meta-analysis of risk factors for peptic ulcer. Nonsteroidal antiinflammatory drugs, helicobacter pylori, and smoking.J Clin Gastroenterol 1997; 24: 2-17.

9. Ashley MJ. Smoking and gastrointestinal system: an epidemiological review with special reference to sex differences. Can J Gastroenterol 1997; 11: 345-52.

10. Sugisawa A, Uehata T. Onset of peptic ulcer and its relation to work-related factors and life events: a prospective study. J Occup Health 1998; 40: 22-31.
11. Uehata T, Yamasaki Y, Sakano J et al. An Epidemiological Survey on Work Stress and Health in Various Kinds of Occupations of Japan First Report.Tokyo:Institute of Industrial Medicare 1991 (in Japanese).

12. Uehata T. Karoshi: occupational stress-related cardiovascular disease.Igaku No Aumi 1990; 153: 238-42 (in Japanese).

13. Aldoori WH, Giovannucci EL, Stampfer MJ, Rimm EB, Wing AL, Willett WC. A prospective study of alcohol, smoking, caffeine, and the risk of duodenal ulcer in man. Epidemiology 1997; 8: 420-24.

14. Brenner $H$, Rothenbacher D, Bode G, Adler G. Relation of smoking and coffee consumption to active Helicobacter pylori infection: cross sectional study. Br Med J 1997; 315: 1489-92.

15. Rothman KJ, Greenland S. Modern Epidemiology, Second Edition. Philadelphia: Lippincott-Raven, 1998.

16. SPSS Inc. SPSS for Windows Professional Statistics, release 7.5.Chicago: SPSS Inc., 1997.

17. The Division of Surveillance and Epidemiology Program Office, Center for Disease Control and Prevention. Epi Info, Version 6.Atlanta, Georgia: The Division of Center for Disease Control and Prevention, 1994.

18. Araki $\mathrm{S}$. The factors affecting gastric and duodenal ulcers in Japanese factory workers, a case-control study Jpn J Ind Health $1985 ; 27: 242-47$.

19. Anda RF, Willamson DF, Escobed LG, Remington PL, Mast EE, Madans JH. Self-perceived stress and the risk of peptic ulcer disease, a longitudinal study of US adults. Arch Intern Med1992; 152: 829-33.

20. House JS, Wells JA, Landerman LR, McMichael, AJ, Kaplan BH. Occupational stress and health among factory workers. J Health and Soc Behav 1979; 20: 139-60.

21. Van der Hust RW, Tytgat GN.Helicobacter pylori and peptic ulcer disease.Scand J Gastroenterol 1996; 220 (Suppl.): 10-18.

22. Blum $\mathrm{AL}$. Helicobacter pylori and peptic ulcer disease. Scand J Gastroenterol 1996; 214 (Suppl.): 24-27.

23. Peuda DA. Helicobacter pylori and ulcerogenesis. Am J Med 1996; 100: 19-25.

24. Laine LA. Helicobacter pylori and complicated ulcer disease. Am J Med 1996; 100: 52-57.

25. Feldman M, Peterson WL. Helicocacter pylori and peptic ulcer disease. West J Med 1993; 159: 555-59.

26. Shigemi J, Mino Y, Tsuda T, Babazono A, Aoyama $H$. The relationship between job stress and mental health at work. Ind Health 1997; 35: 29-35.

27. Mino Y, Shigemi J, Tsuda T, Yasuda N, Bebbington P. Perceived job stress and mental health in precision machine workers of Japan: a 2-year cohort study. Occup Environ Med 1999; 56: 41-45. 